\title{
Impact of satisfaction with physician- patient communication on self-care and adherence in patients with hypertension: cross-sectional study
}

\author{
Natalia Świątoniowska-Lonc ${ }^{1}$, Jacek Polański², Wojciech Tański ${ }^{3}$ and Beata Jankowska-Polańska ${ }^{1 *}$
}

\begin{abstract}
Background: Hypertension (HT) requires patients to continuously monitor their blood pressure, strictly adhere to therapeutic recommendations, and self-manage their illness. A few studies indicate that physician-patient communication and the patient's satisfaction with the therapeutic relationship may affect the course and outcomes of the treatment process. Research is still lacking on the association between satisfaction with physician-patient communication and adherence to treatment or self-care in chronically ill patients. The aim of the study was to evaluate the relationship between satisfaction with physician-patient communication and self-care and adherence in patients with HT undergoing chronic treatment.
\end{abstract}

Methods: The following instruments were used: the Adherence to Refills and Medication Scale (ARMS) for evaluating adherence (12-48 points), the Self-Care of Hypertension Inventory (SCHI) for self-care level (0-100 points), and the Communication Assessment Tool (CAT) for evaluating satisfaction with physician-patient communication. Socio-demographic and clinical data were obtained from patients' medical records. The research has a cross-sectional and observational study design. Inclusion criteria were as follows: age > 18 years, hypertension diagnosed per European Society of Hypertension (ESH) guidelines, treatment with at least one antihypertensive drug for the past 6 months, and informed consent. Cognitively impaired patients unable to complete the surveys without assistance were excluded (MMSE $\leq 18$ ). Correlations between quantitative variables were analyzed using Pearson's or Spearman's correlation coefficient. Linear regression was performed. Variable distribution normality was verified using the Shapiro-Wilk test.

Results: The study included 250 patients (110 male, mean age $61.23 \pm 14.34$ ) with $\mathrm{HT}$, treated at a hypertension clinic. In the CAT questionnaire individual questions pertaining to satisfaction with physician communication (on the CAT) were rated "excellent" $28.4-50.4 \%$ of the time. The best-rated aspects of communication included: letting the patient talk without interruptions (50.4\% "excellent" ratings), speaking in a way the patient can understand (47.6\%), and paying attention to the patient (47.2\%). According to patient reports, physicians most commonly omitted such aspects as encouraging the patient to ask questions (28.4\%), involving them in decisions (29.2\%), and (Continued on next page)

\footnotetext{
* Correspondence: beata.jankowska-polanska@umed.wroc.pl

'Department of Clinical Nursing, Faculty of Health Science, Wroclaw Medical University, K. Bartla 5, 51-616, Wroclaw, Poland

Full list of author information is available at the end of the article
}

(c) The Author(s). 2020 Open Access This article is licensed under a Creative Commons Attribution 4.0 International License, which permits use, sharing, adaptation, distribution and reproduction in any medium or format, as long as you give appropriate credit to the original author(s) and the source, provide a link to the Creative Commons licence, and indicate if changes were made. The images or other third party material in this article are included in the article's Creative Commons licence, unless indicated otherwise in a credit line to the material. If material is not included in the article's Creative Commons licence and your intended use is not permitted by statutory regulation or exceeds the permitted use, you will need to obtain permission directly from the copyright holder. To view a copy of this licence, visit http://creativecommons.org/licenses/by/4.0/ The Creative Commons Public Domain Dedication waiver (http://creativecommons.org/publicdomain/zero/1.0/) applies to the data made available in this article, unless otherwise stated in a credit line to the data. 


\begin{abstract}
(Continued from previous page)
discussing the next steps (35.2\%). The respondents had a low level of adherence to pharmaceutical treatment

(16.63 \pm 4.6$)$. In terms of self-care, they scored highest in self-care management (64.17 \pm 21.18$)$, and lowest in self-

care maintenance $(56.73 \pm 18.57)$. In correlation analysis, satisfaction with physician-patient communication (total

CAT score) was positively correlated with all SCHI domains (self-care maintenance $\beta=0.276$, self-care management

$\beta=0.208$, self-care confidence $\beta=0.286, p<0.05$ ), and negatively correlated with ARMS scores (indicating better adherence).
\end{abstract}

Conclusions: Satisfaction with physician-patient communication has a significant impact on self-care and pharmaceutical adherence in patients with hypertension. The more satisfied the patient is with communication, the better their adherence and self-care.

Trial registration: SIMPLE: RID.Z501.19.016.

Keywords: Adherence, Communication, Self-care, Hypertension

\section{Background}

Hypertension (HT) is a global health and economic problem [1]. According to WHO data, high blood pressure (BP) accounts for $13 \%$ of all deaths worldwide [1]. By 2025, an estimated 1.5 billion people worldwide will have HT [2]. Untreated HT leads to a number of debilitating complications such as chronic heart disease, stroke, coronary heart disease, retinopathy and reduced kidney function [3]. HT treatment is most effective when the patient is cooperative and fully involved in the treatment process, which includes adhering to treatment, performing self-care, and monitoring signs of high blood pressure [4].

Self-care is a key element in the long-term management of chronic diseases and is defined as a process of maintaining health through health-promoting practices and disease management $[5,6]$. Selfcare can be seen as an overarching structure built on 3 key concepts of selfcare maintenance (e.g. observing self-care behaviors such as regular exercise and taking medication as recommended), monitoring (e.g. regular change measurements, routine tests) and management (e.g. change of diet or medication dose based on detection and interpretation of 71 symptoms). The 3 concepts of self-care maintenance, monitoring, and management are closely related; therefore, sufficient self-care includes all three behaviors [5, 6]. Though evidence-based self-care behaviors in HT allow for normalizing BP, patients with HT do not typically adhere fully to these behaviors. In case of primary hypertension self-care involves lifestyle changes, including proper diet and weight control, and pharmaceutical adherence $[7,8]$. Together, these behaviors contribute to better BP control and symptom monitoring. Poor patient cooperation in the treatment process is associated with poor outcomes such as patient recall, patient understanding, and patient adherence to therapy [9]. Nonadherence to treatment is the most common cause of treatment failure. Research has identified multiple factors with an impact on adherence and self-care $[6,10-$
14]. The WHO has defined five groups of factors contributing to non-adherence: (1) patient and familydependent factors, (2) illness-related factors, (3) treatment-related factors, (4) healthcare system-related factors, and (5) socio-demographic and economic factors [15]. Healthcare system-related factors include communication and satisfaction with treatment.

The role of socio-demographic and clinical, patientrelated, and illness-related factors is studied quite often $[16,17]$. Research is still lacking, however, on factors related to the healthcare system, and in particular, satisfaction with treatment and with physician-patient communication. Physician-patient communication has a number of functions, including exchanging information, managing the patient's uncertainty, promoting selfmanagement, addressing emotions, improving the physician-patient relationship, and making decisions [18]. For patients, what matters in the communication process is a sense of being a partner in their treatment process, and a feeling of having their needs understood by medical personnel [19].

Effective physician-provider communication results in better psychological, somatic and social health [20]. In the communication process, the physician may promote positive motivations and patient involvement in the treatment. The patient must understand their illness, the associated risks, and the benefits of consistent treatment. It is important to understand the preferences and beliefs and perspectives of patient health evaluation. In the therapeutic process, the doctor and the patient do not always gain mutual understanding, and their expectations, perspectives may be completely different. The process of mutual communication aims to stimulate or strengthen the sense of control over health, the ability to recognize symptoms and self-care. It is important to note that communication should produce or strengthen a sense of control over the illness, and an ability to identify symptoms and changes in one's condition [21]. 
The available data [14, 22-25], which come mainly from the US, document the role of communication in the physician-patient relationship. Few European reports are available $[14,25]$, and to the best of our knowledge, there have been no Polish studies focusing on the relationship between communication and adherence or self-care in patients with HT.

\section{Methods}

\section{Aim}

The aim of the study was to evaluate the relationship between satisfaction with physician-patient communication and self-care and adherence in patients with HT undergoing chronic treatment.

The primary outcome of our study was the perceived quality of the physician-patient communication. The secondary outcome was the relationship between physician-patient communication on the one hand, and pharmaceutical adherence and self-care on the other.

\section{Design}

The present research has a cross-sectional and observational study design. Data were collected between January 2019 and August 2019 from patients who reported for follow-up appointments at the clinical division of internal medicine with specialization in hypertension. The study used a closed-ended standardized survey.

\section{Data collection}

\section{Participants}

The study included 250 patients (110 male) diagnosed with HT per European Society of Cardiology (ESC) guidelines [4].

Inclusion criteria were as follows: age above 18 years, hypertension diagnosed per European Society of Hypertension (ESH) guidelines, treatment with at least one antihypertensive drug for the past 6 months, and informed consent. Patients with exacerbations of other serious diseases, which could affect adherence to treatment and/or interfere with survey completion, were excluded from the study. Cognitively impaired patients unable to complete the surveys without assistance were also excluded (patients aged 65 or more were tested using the MMSE questionnaire, and those with scores $\leq 18$ were excluded from the study).

Patients were selected by a panel consisting of a physician and a nurse-specialist in the field of internal medicine. The personnel were informed about the aim of the study. A study protocol was prepared for the purpose of the study so that the personnel could collect data in the same way. Respondents answered all questions directly, based on their last 4 weeks of treatment. Patients filled in the questionnaire on their own in the paper version. Patients not able to complete the questionnaire on their own due to their health condition were excluded. The nurse was always available and helpful but did not fill in the questionnaires with the patient. Patients were informed that they could contact a nurse specialist (available in the clinic) if they needed any clarification or guidance related to the survey. Socio-demographic and clinical data were obtained from the patients' medical records, with their consent.

In the study period (January-August 2019), 323 patients with hypertension diagnosed in accordance with the ESC criteria were hospitalized in the department. In this group, 40 patients did not meet the inclusion criteria, and 26 refused to participate. Therefore, $257 \mathrm{pa}$ tients were included in the study and received surveys; however, during the study, 7 patients dropped out without providing a reason or did not complete the survey correctly. The final group included 250 patients. All patients were informed about the study course and methods, and about the possibility of withdrawing from the study at any time.

\section{Instruments}

The following standardized questionnaires were used:

(1) The Communication Assessment Tool (CAT), comprising 14 items for evaluating the quality of specific aspects of physician-patient communication. Responses are provided using a 5 -item Likert scale, from 1 (poor) to 5 (excellent). Higher percentages of "excellent" scores indicate more satisfaction with communication. The original version of the Communication Assessment Tool is internally consistent, with a high scale reliability (Cronbach's coefficient alpha $=0.98)$ [26].

(2) The Adherence to Refills and Medication Scale (ARMS), which evaluates the patient's adherence level. It comprises 12 items related to various aspects of nonadherence, scored on the following scale: $1-$ never, 2 - rarely, 3 - often, 4 - most of the time. Therefore, total scores range between 12 and 48 points, with higher scores indicating poorer adherence. In the polish version of ARMS-12 reliability analysis, standardized Cronbach's $\alpha$ was 0.954 [11].

(3) The Self-Care of Hypertension Inventory (SCHI), which enables the evaluation of a hypertensive patient's independence in three aspects of daily functioning with the illness: self-management, self-maintenance, and selfconfidence. Scores in each aspect range from 0 to 100 , with higher scores indicating more independence in the relevant aspect. In the original version of SCHI a unidimensional confidence factor captured confidence in and persistence with each aspect of self-care $(\alpha=0.83)$ [5].

\section{Ethical consideration}

The study was approved by the local Bioethics Committee (approval no. KB 42/2019). All participants provided 
written informed consent after a thorough explanation of all procedures involved. All patients received information about the purpose and nature of the study and provided written informed consent to participate. All patients completed all questionnaires. The study was carried out in accordance with the tenets of the Declaration of Helsinki.

\section{Statistical analysis}

Patients were broken down into two groups: group $1-$ poor communication $(n=34)$, group $2-$ good communication $(n=216)$.

Correlations between quantitative variables were analyzed using Pearson's correlation coefficient (if distributions for both were normal) or Spearman's correlation coefficient (otherwise) [27]. Multivariate analysis of the independent impact of the selected variables on the quantitative variable was performed using linear regression. The results are shown as regression model parameter values with a $95 \%$ confidence interval (CI). Variable distribution normality was verified using the ShapiroWilk test. All analyses used a significance threshold of 0.05 . i.e. all $p$ values of less than 0.05 were interpreted as showing significant associations. The analyses were performed using the R software, version 3.6.0 [28].

\section{Results}

\section{Socio-demographic and clinical characteristics of the group}

The study included 250 patients (110 male) with a mean age of $61.23 \pm 14.34$ years. Comparative analysis demonstrated significant differences in patients' sociodemographic and clinical characteristics (Table 1). Patients were divided into two groups according to the sum of answers given - poor communication (0-42 points), good communication (43-70 points). Patients reporting poor communication with the physician were older ( $65.68 \pm 10.69$ vs. $60.53 \pm 14.73$ years), spent less time in an appointment (16.21 \pm 9.52 vs. $20.08 \pm 10.13$ min), and discussed their problems for a shorter time during an appointment (7.38 \pm 7.22 vs. $10.43 \pm 9.39 \mathrm{~min})$ compared to those reporting good physician-patient communication. The groups did not differ in terms of the remaining variables.

\section{Satisfaction with physician-patient communication}

In the CAT questionnaire individual questions pertaining to satisfaction with physician communication (on the CAT) were rated "excellent" $28.4-50.4 \%$ of the time. The best-rated aspects of communication included: letting the patient talk without interruptions (50.4\% "excellent" ratings), speaking in a way the patient can understand (47.6\%) and paying attention to the patient (47.2\%). According to patient reports, physicians most commonly omitted such aspects as encouraging the patient to ask questions (28.4\%), involving them in decisions (29.2\%), and discussing next steps (35.2\% Table 2).

\section{Self-care and adherence to pharmaceutical treatment depending on satisfaction with communication}

SCHI scores in the entire group showed that patients fared best in terms of self-care management $(64.17 \pm$ $21.18)$, and worst in terms of self-care maintenance (56.73 \pm 18.57$)$ (Table 3). The evaluation of pharmaceutical adherence levels using the ARMS questionnaire demonstrated good adherence in the group studied (Table 3). The mean score on the ARMS questionnaire was $16.63(\mathrm{SD}=4.6)$. The mean score per item was 1.39 , indicating that most patients "never" or "rarely" failed to adhere to treatment.

When comparing results between groups broken down by patient-provider communication quality, higher selfcare and adherence levels were found in the "good communication" group, with statistically significant differences between the two groups in terms of self-care confidence $(p=0.005)$, and not significant differences in terms of self-care management $(p=0.059)$.

Self-care in the specific domains was correlated with odds of good communication. Factors with an impact on this parameter included self-care management $(\mathrm{OR}=$ 1.019), self-care confidence ( $\mathrm{OR}=1.021)$, and adherence score in the ARMS $(\mathrm{OR}=0.905)$ (Table 4). Each additional point in the self-care management domain increased the odds of good communication by $1.9 \%$, and in the self-care confidence domain - by $2.1 \%$. Higher scores in the ARMS (i.e. poorer adherence) decreased the odds of good communication by $9.5 \%$.

\section{Impact of communication on self-care and adherence}

In the correlation analysis, satisfaction with communication scores on the CAT questionnaire were significantly positively correlated with all SCHI domains (self-care maintenance $r=0.208$, self-care management $r=0.276$, self-care confidence $r=0.284$ ), i.e. more satisfaction with communication was associated with better self-care in all SCHI domains (Table 4). The correlation between satisfaction with communication and pharmaceutical adherence (ARMS score) is statistically significant and negative $(r=-0.299, p<0.001)$, i.e. more satisfaction with communication was associated with lower ARMS score, indicating better adherence (Table 5).

\section{Discussion}

To the best of our knowledge, ours is the first study (based on polish patients) to identify communication between the physician and the patient as a significant 
Table 1 Socio-demographic and clinical characteristics of the study group

\begin{tabular}{|c|c|c|c|c|}
\hline Variable & & $\begin{array}{l}\text { Poor communication } \\
(n=34)\end{array}$ & $\begin{array}{l}\text { Good communication } \\
(n=216)\end{array}$ & $p$ \\
\hline Age & mean $\pm S D$ & $65.68 \pm 10.69$ & $60.53 \pm 14.73$ & $\begin{array}{l}0.049 \\
\text { NP }\end{array}$ \\
\hline Duration of $\mathrm{HT}$ in years & mean $\pm S D$ & $10.24 \pm 10.77$ & $12.4 \pm 10.34$ & $\begin{array}{l}0.124 \\
\text { NP }\end{array}$ \\
\hline Appointment duration [min] & mean $\pm S D$ & $16.21 \pm 9.52$ & $20.08 \pm 10.13$ & $\begin{array}{l}0.008 \\
N P\end{array}$ \\
\hline $\begin{array}{l}\text { Time spent discussing the patient's } \\
\text { problems [min] }\end{array}$ & mean $\pm S D$ & $7.38 \pm 7.22$ & $10.43 \pm 9.39$ & $\begin{array}{l}0.037 \\
N P\end{array}$ \\
\hline \multirow[t]{2}{*}{ Sex } & Female & 18 (52.94\%) & $122(56.48 \%)$ & 0.841 \\
\hline & Male & $16(47.06 \%)$ & $94(43.52 \%)$ & chi2 \\
\hline \multirow[t]{2}{*}{ Place of residence } & Rural & $6(17.65 \%)$ & $51(23.61 \%)$ & 0.582 \\
\hline & Urban & $28(82.35 \%)$ & $165(76.39 \%)$ & chi2 \\
\hline \multirow[t]{2}{*}{ Relationship status } & Single & $9(26.47 \%)$ & 65 (30.09\%) & 0.82 \\
\hline & In a relationship & $25(73.53 \%)$ & $151(69.91 \%)$ & chi2 \\
\hline \multirow[t]{3}{*}{ Education } & Primary or none & $3(8.82 \%)$ & $20(9.26 \%)$ & 0.762 \\
\hline & High school & $20(58.82 \%)$ & $112(51.85 \%)$ & $\mathrm{F}$ \\
\hline & College/university & $11(32.35 \%)$ & $84(38.89 \%)$ & \\
\hline \multirow[t]{4}{*}{ Professional status } & Professionally active & $9(26.47 \%)$ & $77(35.65 \%)$ & 0.338 \\
\hline & Retirement pensioner & $20(58.82 \%)$ & $96(44.44 \%)$ & $\mathrm{F}$ \\
\hline & Disability pensioner & $3(8.82 \%)$ & $34(15.74 \%)$ & \\
\hline & Unemployed & $2(5.88 \%)$ & $9(4.17 \%)$ & \\
\hline \multirow[t]{5}{*}{ Financial standing } & Wealthy & $0(0.00 \%)$ & $12(5.56 \%)$ & 0.723 \\
\hline & $\begin{array}{l}\text { Able to afford all that is needed and save } \\
\text { some money }\end{array}$ & $14(41.18 \%)$ & $83(38.43 \%)$ & $\mathrm{F}$ \\
\hline & $\begin{array}{l}\text { Able to afford daily expenses, but not any } \\
\text { larger ones }\end{array}$ & $17(50.00 \%)$ & $93(43.06 \%)$ & \\
\hline & Unable to afford many things & $3(8.82 \%)$ & $25(11.57 \%)$ & \\
\hline & $\begin{array}{l}\text { Unable to afford even the most basic } \\
\text { expenses }\end{array}$ & $0(0.00 \%)$ & $3(1.39 \%)$ & \\
\hline \multirow[t]{5}{*}{ Frequency of follow-up appointments } & 1 & $3(8.82 \%)$ & $12(5.56 \%)$ & 0.557 \\
\hline & $1-2$ & $4(11.76 \%)$ & $39(18.06 \%)$ & $\mathrm{F}$ \\
\hline & $4-5$ & $9(26.47 \%)$ & $38(17.59 \%)$ & \\
\hline & More than 5 & $18(52.94 \%)$ & $124(57.41 \%)$ & \\
\hline & None & $0(0.00 \%)$ & $3(1.39 \%)$ & \\
\hline \multirow[t]{3}{*}{ BMI: } & Normal weight & 7 (20.59\%) & 65 (30.09\%) & 0.514 \\
\hline & Overweight & $15(44.12 \%)$ & $81(37.50 \%)$ & chi2 \\
\hline & Obesity & $12(35.29 \%)$ & $70(32.41 \%)$ & \\
\hline \multirow[t]{2}{*}{ BP } & Normal BP & $22(64.71 \%)$ & $120(55.56 \%)$ & 0.415 \\
\hline & Elevated BP & $12(35.29 \%)$ & $96(44.44 \%)$ & chi2 \\
\hline
\end{tabular}

$P$ normal (parametric) distribution in groups, Student's t-test; NP non-parametric distribution in groups, Mann-Whitney test, $B P$ blood pressure, $H T$ hypertension, BMI Body Mass Index

predictor of adherence to pharmaceutical treatment and of self-care in patients with HT.

In our study, patients had the best results in selfmanagement, and the most difficulties in selfmaintenance. Research shows an association between self-maintenance and good BP control [29]. In a study by Logan et al., $51 \%$ of patients in a group provided with education on BP measurement achieved the target of < $130 / 80 \mathrm{mmHg}$, compared to $31 \%$ in the control group [30]. According to Cheng, patients are ambivalent about measuring their $\mathrm{BP}$ at home: despite access to a $\mathrm{BP}$ meter and encouragement from their physician, only a 
Table 2 CAT scores

\begin{tabular}{lll}
\hline Item & & \% of "excellent" scores \\
\hline 1 & The physician greeted me in a way that made me feel comfortable & $38.4 \%$ \\
3 & The physician treated me with respect & $46.0 \%$ \\
4 & The physician showed interest in my ideas about my health & $44.8 \%$ \\
5 & The physician understood my main health concerns & $44.8 \%$ \\
6 & The physician paid attention to me (looked at me, listened carefully) & $47.2 \%$ \\
7 & The physician let me talk without interruptions & $50.4 \%$ \\
8 & The physician gave me all the information I wanted & $40.8 \%$ \\
9 & The physician talked in terms I could understand & $47.6 \%$ \\
10 & The physician checked to be sure I understood everything & $39.2 \%$ \\
11 & The physician encouraged me to ask questions & $28.4 \%$ \\
13 & The physician involved me in decisions & $29.2 \%$ \\
\hline 14 & The physician discussed next steps, including any follow-up plans & $35.2 \%$ \\
\hline
\end{tabular}

third actually report their home readings to the physician. What is worse, as many as $40 \%$ take no action whatsoever to normalize their BP [31]. In other studies, the percentage of hypertensive patients with good selfcare practices ranged between 20.3 and $37.1 \%$ [8, 32]. In their study of patients with HT, Gebremichael et al. demonstrated an association between good self-care practices and good BP control [32].

Our study was performed in a secondary care setting, where patients are seen less frequently. A large proportion of care is provided in primary care settings. This is the first line of monitoring the patients' health, with broader possibilities of providing constant care, monitoring lifestyle changes, and correcting patients' behaviors. In our study, discussing the next steps or follow-up plans was among the most commonly omitted aspects of the appointments (35.2\%). Mendes et al. compared selfcare levels of HT patients in primary and secondary healthcare settings. Patients using primary care services adhered to fluid restrictions and kept follow-up appointments significantly more often than those in secondary care. Other self-care components did not differ between the groups [10]. One could infer that patients treated in a secondary care setting have a more advanced clinical condition (complications, multimorbidity), warranting the higher referral level.

In our study, the mean pharmaceutical adherence score was $16.63 \pm 4.6$, indicating satisfactory adherence. Compared to other Polish studies on HT patients, we found higher adherence levels based on the patient profile - female sex, age below 65 , being in a relationship, having a high school or college/university education, and normal BP levels $[11-13,16]$. In the literature, there are many studies on adherence among patients with HT. Nearly $50 \%$ of patients do not take their medications as prescribed [1]. Non-adherence to HT treatment results in uncontrolled BP $[11,12]$. Compared to literature reports, we found more satisfactory adherence levels - in the literature, more than half of patients do not take their medication, and even among those who do, the results are poor [16].

Communication between health care personnel and the patient has a significant impact on the patient's attitude towards their illness [33]. The primary aim of our

Table 3 Comparison of self-care and adherence levels between groups broken down by satisfaction with patient-provider communication

\begin{tabular}{|c|c|c|c|c|c|c|c|}
\hline \multirow[t]{2}{*}{ SC-HI } & \multicolumn{2}{|c|}{ All patients $N=250$} & \multicolumn{2}{|c|}{ Poor communication (CAT 0-42) N=34 } & \multicolumn{2}{|c|}{ Good communication (CAT 43-70) $N=216$} & \multirow[t]{2}{*}{$p$} \\
\hline & Mean & SD & Mean & SD & Mean & SD & \\
\hline Self-care maintenance & 56.73 & 18.57 & 53.12 & 16.67 & 57.3 & 18.82 & $0.224^{*}$ \\
\hline Self-care management & 64.17 & 21.18 & 56.62 & 22.54 & 65.36 & 20.77 & $0.059^{* *}$ \\
\hline Self-care confidence & 62.47 & 24.39 & 51.47 & 26.03 & 64.2 & 23.72 & $0.005^{* *}$ \\
\hline ARMS [points] & 16.63 & 4.6 & 18.88 & 5.76 & 16.28 & 4.3 & $0.104^{* *}$ \\
\hline
\end{tabular}

* Normal distribution in groups, Student's t-test; ${ }^{* *}$ lack of normal distribution in groups, Mann Whitney test, SD standard deviation, SC-HI The Self-Care of Hypertension Inventory, ARMS The Adherence to Refills and Medication Scale, CAT The Communication Assessment 
Table 4 Odds ratios for good communication

\begin{tabular}{lllll}
\hline Variable & OR & $\mathbf{9 5 \% ~ C l}$ & & $\boldsymbol{p}^{*}$ \\
\hline SC-HI: Self-care maintenance & 1.012 & 0.993 & 1.033 & 0.224 \\
SC-HI: Self-care management & 1.019 & 1.002 & 1.036 & 0.027 \\
SC-HI: Self-care confidence & 1.021 & 1.006 & 1.036 & 0.006 \\
ARMS & 0.905 & 0.847 & 0.968 & 0.004 \\
\hline
\end{tabular}

* single-factor logistic regression, $O R$ odds ratio, $\mathrm{Cl}$ confidence interval, SC-HI The Self-Care of Hypertension Inventory, ARMS The Adherence to Refills and Medication Scale, CAT The Communication Assessment

study was to evaluate patients' satisfaction with communication and its impact on their involvement in the treatment process. Studies on patients with diabetes mellitus confirm the impact of communication on better adherence and self-care in chronically-ill patients, but also that of adherence and self-care on better physicianpatient communication [34-36]. In a meta-analysis performed by Zolnierek et al., the non-adherence percentage was $19 \%$ higher in those patients who reported poor physician-patient communication [9]. In our study, satisfaction with communication was significantly correlated with all self-care domains and with adherence. In published studies, communication interventions, though differing in methods and content, did affect chronicallyill patients' adherence to treatment [34, 37]. Heisler et al. demonstrated that a higher level of explanatory physician communication was significantly associated with more independence in medication-taking among elderly patients [34]. In addition to diagnosis and treatment, patients expect their primary care physicians to be competent in contact and communication. Patients appreciate the value of talking to their physician, and some even consider it therapeutic in itself [21]. In our study, patients were satisfied with the clarity of communication, the ability to speak without interruption, and the amount of attention they received. Patients value physicians who are good listeners. A physician-patient communication style requires including the patient in treatment planning [21, 38]. In their relationship with the primary care physician, patients may prefer a "partnership" model of care, and some physicians do demonstrate this kind of attitude. However, not all physicians approve of the patient's active participation in consultations [21]. The patients in our study complained of not being included in decision-making (29.2\%). Physician-patient communication may contribute to joint decisions about the treatment. Patients' active attitude and physician-patient communication may also provide the physician with information on the perceived advantages and disadvantages of the proposed treatment course [35]. Ratanawongsa et al. demonstrated an association between a lower level of adherence to refills and physician characteristics such as poor ability to involve patients in decision-making, lack of understanding of patients' problems associated with the treatment, and failure to inspire trust and confidence [36]. In our study, patients most commonly reported not being encouraged to ask questions (only $28.4 \%$ of "excellent" answers). For the physician, patients' answers to their questions are the main source of information. As some patients may lack the courage to ask questions themselves, the physician should encourage them and make them feel comfortable enough to ask questions freely.

Our findings show that the entire communication process, with all its components, plays a role in improving self-care and adherence. Correlation analysis for specific items on the questionnaire did not demonstrate any statistically significant impact on self-care and adherence results, except for the self-management domain. It seems, then, that it is an overall perception of communication as a whole, rather than any specific component, that affects patients' self-care and adherence.

\section{Study limitations}

Our study had a few limitations. One is the lack of a health literacy assessment. Patients' knowledge on health and disease may be a factor facilitating active participation in consultations with a physician [39]. Patients with a low level of health literacy have difficulties communicating with medical personnel [40]. In a study by Ishikawa et al., a more critical approach to analyzing information on diabetes was associated with more knowledge on the illness, a larger number of information sources, and more independence in terms of diabetes self-care, while a higher level of health literacy in the communication domain was correlated with better physician-patient communication

Table 5 Correlation analysis for CAT, SCHI, and ARMS scores

\begin{tabular}{llllll}
\hline Parameter & & Correlation with CAT & & & \\
\cline { 3 - 6 } & & Correlation coefficient & $\boldsymbol{p}^{*}$ & Correlation direction & Correlation strength \\
\hline SC-HI & Self-care maintenance & 0.208 & $p=0.001 \mathrm{NP}$ & positive & very weak \\
& Self-care management & 0.276 & $p<0.001 \mathrm{NP}$ & positive & very weak \\
& Self-care confidence & 0.284 & $p<0.001 \mathrm{NP}$ & positive & very weak \\
& ARMS [points] & -0.299 & $p<0.001 \mathrm{NP}$ & negative & very weak \\
\hline
\end{tabular}

* $P=$ normal (parametric) distribution of both correlated variables, Pearson's correlation coefficient used, $N P=$ non-parametric distribution for at least one of the correlated variables, Spearman's correlation coefficient used, CAT The Communication Assessment, SC-HI The Self-Care of Hypertension Inventory, ARMS The Adherence to Refills and Medication Scale 
during consultations [41]. Another limitation is not analyzing the impact of the patients' sex on physician-patient communication. Women are more likely than men to discuss their problems with their physician, and are more willing to undergo treatment. The sex of the physician could also be a factor. Patients are more willing to talk to female physicians, who in turn are more empathetic towards patients [22].

\section{Conclusions}

Patients with HT treated at a specialist clinic report a high level of satisfaction with communication. The most important aspects from the patients' perspective include the physician speaking in an understandable way and paying attention. The most common complaints include not being encouraged to ask questions and not being included in the treatment plan and decision-making. Satisfaction with physician-patient communication is significantly correlated with better self-care and pharmaceutical adherence in patients with HT. Patients with HT demonstrate a high level of pharmaceutical adherence and self-care skills, especially in terms of self-care management. The lowest self-care quality was found in terms of self-maintenance.

\section{Abbreviations}

ARMS: The Adherence to Refills and Medication Scale; BMI: Body Mass Index; BP: Blood pressure; CAT: The Communication Assessment Tool; Cl: 95\% confidence interval; ESC: The European Society of Cardiology; ESH: The European Society of Hypertension; HT: Hypertension; MMSE: The Mini-Mental State Examination; SCHI: The Self-Care of Hypertension Inventory; SD: Standard deviation; US: The United States; WHO: World Health Organization

\section{Acknowledgements}

Not applicable.

\section{Authors' contributions}

NŚL contributed to the conceptualization, methodology, data analysis and interpretation and original manuscript preparation. JP contributed to the investigation and data curation. WT contributed to the conceptualization, methodology, data analysis of this study and revised the manuscript for important intellectual content. BJP contributed to the conceptualization, methodology of this study and revised the manuscript for important intellectual content. All authors have read and approved the manuscript.

\section{Funding}

This work was supported by the Ministry of Science and Higher Education in the 'Regional Initiative of Excellence' programme, grant number 016/RID/ 2018/19

\section{Availability of data and materials}

The datasets used and/or analyzed during the current study are available from the corresponding author on reasonable request.

\section{Ethics approval and consent to participate}

The study was approved by the Bioethics Committee at Wroclaw Medical University (approval no. KB 42/2019), which requires the consent of the manager of the center where patients' data are collected. Each patient has signed a written informed consent and medical data obtained from hospital records are protected due to the implemented data protection procedures. All procedures followed were in accordance with the ethical standards of the responsible committee on human experimentation (institutional and national) and with the Helsinki Declaration of 1975, as revised in 2000.
Consent for publication

Not applicable.

\section{Competing interests}

The authors declare that they have no competing interests.

\section{Author details}

${ }^{1}$ Department of Clinical Nursing, Faculty of Health Science, Wroclaw Medical University, K. Bartla 5, 51-616, Wroclaw, Poland. ${ }^{2}$ Faculty of Medicine, Wroclaw Medical University, Wroclaw, Poland. ${ }^{3}$ Department of Internal Medicine, 4th Military Teaching Hospital, Wroclaw, Poland.

Received: 12 May 2020 Accepted: 10 November 2020

Published online: 16 November 2020

References

1. Sabaté $E$, editor. Adherence to long-term therapies: evidence for action. Geneva: World Health Organization; 2003.

2. Suligowska K, Gajewska M, Stokwiszewski J, Gaciong Z, Bandosz P, et al. Insufficient knowledge of adults in Poland on criteria of arterial hypertension and its complications - results of the NATPOL 2011 survey. Arterial Hypertension. 2014;18(1):9-18.

3. Mendis S. World Health Organisation; 2010. Global status report on non communicable diseases 2010. http://www.who.int/nmh/publications/ncd report2010/en/ (Accessed: 03.10.2020).

4. Williams B, Mancia G, Spiering W, Agabiti Rosei E, Azizi M, Burnier M, et al. 2018ESC/ESH guidelines for the management of arteria hypertension: the task force for the management of arterial hypertension of the European Society of Cardiology and the European Society of Hypertension: the task force for the management of arterial hypertension of the European Society of Cardiology and the European Society of Hypertension. J Hypertens. 2018; 36(10):1953-2041

5. Dickson W, Lee C, Yehle KS, Abel WM, Riegel B. Psychometric testing of the self-care of hypertension inventory. J CardiovascNurs. 2017;32(5):431-8.

6. Riegel B, Moser DK, Buck HG, Dickson W, Dunbar SB, Lee CS, et al. Self-Care for the Prevention and Management of cardiovascular disease and stroke a scientific statement for healthcare professionals from the American Heart Association. J Am Heart Assoc. 2017;6(9):e006997. https://doi.org/10.1161/ JAHA.117.006997

7. Hu H, Li G, Arao T. Prevalence rates of self-care behaviors and related factors in a rural hypertension population: a questionnaire survey. Int J Hypertens. 2013;2013:526949.

8. Bilal M, Haseeb A, Lashkerwala SS, Zahid I, Siddiq K, Saad M, et al. Knowledge, awareness and self-care practices of hypertension among cardiac hypertensive patients. Global J Health Sci. 2016;8(2):9.

9. Zolnierek KB, Dimatteo MR. Physician communication and patient adherence to treatment: a meta-analysis. Med Care. 2009;47(8):826-34.

10. Mendes CR, Souza TL, Felipe GF, Lima FE, Miranda MD. Self-care comparison of hypertensive patients in primary and secondary health care services. Acta Paul Enferm. 2015;28(6):580-6.

11. Lomper K, Chabowski M, Chudiak A, Białoszewski A, Dudek K, JankowskaPolańska B. Psychometric evaluation of the polish version of the adherence to refills and medications scale (ARMS) in adults with hypertension. Patient Prefer Adherence. 2018;12:2661-70. https://doi.org/10.2147/PPA.S185305 ecollection 2018

12. Jankowska-Polanska B, Uchmanowicz I, Chudiak A, Dudek K, Morisky DE, Szymanska-Chabowska A. Psychometric properties of the polish version of the eight-item Morisky medication adherence scale in hypertensive adults. Patient Prefer Adherence. 2016;10:1759-66.

13. Choi HY, Oh IJ, Lee JA, Lim J, Kim YS, Jeon TH, Cheong YS, Kim DH, Kim MC, Lee SY. Factors affecting adherence to antihypertensive medication. Korean J Fam Med. 2018;39(6):325-32.

14. Zanatta F, Nissanova E, Świątoniowska-Lonc N, Pierobon A, Callegari G, Olmetti F, et al. Psychosocial Predictors of Self-Efficacy Related to SelfReported Adherence in Older Chronic Patients Dealing with Hypertension: A European Study. Patient Pref Adh. 2020;2020;(14):1709-18. https://doi.org/ 10.2147/PPA.S258999.

15. Chaudri NA. Adherence to long-term therapies evidence for action. Ann Saudi Med. 2004;24(3):221-2. https://doi.org/10.5144/0256-4947.2004.221.

16. Jankowska-Polańska B, Chudiak A, Uchmanowicz I, Dudek K, Mazur G. Selected factors affecting adherence in the pharmacological 
treatment of arterial hypertension. Patient Prefer Adherence. 2017;11: 363-71.

17. Gast A, Mathes T. Medication adherence influencing factors - an (updated) overview of systematic reviews. SystRev. 2019;8(1):112.

18. Epstein RM, Fiscella K, Lesser CS, Stange KC. Why the nation needs a policy push on patient-centered health care. Health Affairs (Millwood). 2010;29(8): 1489-95.

19. Keating NL, Gandhi TK, Orav EJ, Bates DW, Ayanian JZ. Patient characteristics and experiences associated with trust in specialist physicians. Arch Intern Med. 2004;164:1015-20.

20. Choi E, Chentsova-Dutton Y, Parrott WG. The effectiveness of somatization in communicating distress in Korean and American cultural contexts. Front Psychol. 2016;7:383. https://doi.org/10.3389/fpsyg.2016.00383.

21. Świątoniowska N, Sarzyńska K, Szymańska-Chabowska A, JankowskaPolańska B. The role of education in type 2 diabetes treatment. Diabetes Res ClinPract. 2019;151:237-46. https://doi.org/10.1016/j.diabres. 2019.04.004.

22. Bylund $\mathrm{CL}$, Makoul G. Empathic communication and gender in the physician-patient encounter. PatientEducCouns. 2002;48(3):207-16.

23. Haskard KB, Williams SL, DiMatteo MR, Rosenthal R, White MK, Goldstein MG. Physician and patient communication training in primary care: effects on participation and satisfaction. Health Psychol. 2008;27(5):513-22. https://doi. org/10.1037/0278-6133.27.5.513.

24. Kenny DA, Veldhuijzen W, van der Weijden T, Leblanc A, Lockyer J, Légaré F, et al. Interpersonal perception in the context of doctor-patient relationships: a dyadic analysis of doctor-patient communication. Soc Sci Med. 2010;70(5): 763-8. https://doi.org/10.1016/j.socscimed.2009.10.065.

25. Maatouk-Bürmann B, Ringel N, Spang J, Weiss C, Möltner A, Riemann U, et al. Improving patient-centered communication: results of a randomized controlled trial. Patient Educ Couns. 2016;99(1):117-24. https://doi.org/10. 1016/j.pec.2015.08.012

26. Makoul G, Krupat E, Chang CH. Measuring patient views of physician communication skills: development and testing of the communication assessment tool. Patient EducCouns. 2007;67(3):333-42.

27. Hinkle DE, Wiersma W, Jurs SG. Applied statistics for the behavioral sciences. 5th ed. Boston: Houghton Mifflin; 2003.

28. R Core Team. In: https://www.R-project.org/ (Accessed: 03.10.2020), editor. R: a language and environment for statistical computing. Vienna: $R$ Foundation for Statistical Computing; 2019.

29. Wang W, Lau Y, Loo A, et al. Medication adherence and its associated factors among Chinese community-dwelling older adults with hypertension. Heart Lung. 2014;43:278-83.

30. Logan AG, Irvine MJ, Mclsaac WJ, Tisler A, Rossos PG, Easty A, Feig DS, Cafazzo JA. Effect of home blood pressure telemonitoring with self-care support on uncontrolled systolic hypertension in diabetics. Hypertension. 2012;60(1):51-7.

31. Cheng C, Studdiford JSA, Diamond JJ, Chambers CV. Primary care physician beliefs regarding usefulness of self-monitoring of blood pressure. Blood Press Monit. 2003;8:249-54.

32. Gebremichael GB, Berhe KK, Beyene BG, Gebrekidan KB. Self-care practices and associated factors among adult hypertensive patients in Ayder comprehensive specialized hospital, Tigray, Ethiopia, 2018. BMC Res Notes. 2019;12(1):489.

33. Zoppi K, Epstein RM. Is communication a skill? Communication behaviors and being in relation. Fam Med. 2002;34:319-24.

34. Heisler M, Cole I, Weir D, Kerr EA, Hayward RA. Does physician communication influence older patients' diabetes self-management and glycemic control? Results from the health and retirement study (HRS). J Gerontol A Biol Sci Med Sci. 2007;62(12):1435-42.

35. Karter AJ, Subramanian U, Saha C, et al. Barriers to insulin initiation: the translating research into action for diabetes (TRIAD) insulin starts project. Diabetes Care. 2010;33(4):733-5.

36. Ratanawongsa N, Karter AJ, Parker MM, et al. Communication and medication refill adherence: the diabetes study of northern California. J Am Med Assoc Intern Med. 2013;173:210-8.

37. Bukstein DA. Patient adherence and effective communication. Ann AllergyAsthmalmmunol. 2016;117(6):613-9.

38. Jarosz MJ, Kawczyńska-Butrym Z, Włoszczak-Szubzda A. Modele komunikacyjne relacji lekarz - pacjent -rodzina [communications models of physician-patient-family relationship]. Medycyna Ogólna Nauki o Zdrowiu. 2012;3(18):212-8.
39. Nutbeam D. Health promotion glossary. Health Promot Int. 1998;13(4): 349-64.

40. White RO, Wolff K, Cavanaugh KL, Rothman R. Addressing health literacy and numeracy to improve diabetes education and care. Diab Spectr. 2010; 23:238-43.

41. Ishikawa H, Yano E, Fujimori S, Kinoshita M, Yamanouchi T, Yoshikawa M, Yamazaki Y, Teramoto T. Patient health literacy and patient-physician information exchange during a visit. FamPract. 2009;26:517-23.

\section{Publisher's Note}

Springer Nature remains neutral with regard to jurisdictional claims in published maps and institutional affiliations.
Ready to submit your research? Choose BMC and benefit from:

- fast, convenient online submission

- thorough peer review by experienced researchers in your field

- rapid publication on acceptance

- support for research data, including large and complex data types

- gold Open Access which fosters wider collaboration and increased citations

- maximum visibility for your research: over $100 \mathrm{M}$ website views per year

At BMC, research is always in progress.

Learn more biomedcentral.com/submissions 